УДК 82.0

\title{
А.С. Огальцев
}

\section{ОСОБЕННОСТИ ОСМЫСЛЕНИЯ ТВОРЧЕСТВА А.П. ЧЕХОВА В ИСПАНИИ}

В статье рассматривается процесс осмысления испанской культурой творчества А.П. Чехова. Основываясь на отечественных и зарубежных источниках, автор исследования выделяет наиболее значимые моменты в постижении русского писателя и драматурга испанскими литературными критиками, театральными режиссёрами и режиссёрами кино. Даётся краткий обзор ключевых периодических и книжных изданий, спектаклей и экранизаций, которые иллюстрируют собой эволюцию понимания чеховского творчества. В авторском переводе на русский язык представлены цитаты из работ и интервью испанских деятелей культуры, критиков, переводчиков и журналистов. В статье рассмотрен период с момента первого упоминания имени Чехова в испанской прессе в 1894 г. по настоящее время. Отдельное внимание уделяется первым экранизациям пьес русского драматурга и наиболее актуальным экспериментальным постановкам в столичных и провинциальных театрах Испании.

Ключевые слова: творчество Чехова, Чехов в Испании, Чехов и зарубежье, экранизации Чехова, чеховские пьесы.

DOI: $10.35634 / 2412-9534-2020-30-6-1072-1077$

Согласно официально зарегистрированным данным первое упоминание об А.П. Чехове в Испании появилось в 1894 г. в шестом номере журнала «Revista internacional» - в статье «Ссыльные на Сахалине» цитировался один из очерков писателя [2]. В последующие годы в связи с премьерными постановками чеховских пьес в России, в особенности по случаю их успешности на сцене МХТ, испанская пресса давала некоторые заметки, так или иначе затрагивая творчество русского драматурга. Однако впервые по-настоящему ввёл имя А.П. Чехова в испанские литературоведение и критику в 1902 г. историограф, литературный критик и переводчик - Хулиан Худериас [1].

Стоит отметить, что его статья «Tchejoff» не являлась простым переводом какой-либо сторонней публикации, как большинство других, написанных для журнала «La lectura», в котором русской литературе посвящалось немалое количество страниц. Кроме того, данная статья основывалась на мнении многих российских критиков. Испанский исследователь представил достаточно ёмкий и содержательный обзор взглядов на творчество Чехова, которые уже имелись на тот момент в отечественной и зарубежной критике.

Х. Худериас особо отмечал оригинальность русского писателя, которая, как ему казалось, «является главной чертой его характера». Раннего Чехова он называет «изобретательным и искусным», ссылаясь также на мнение Висконда де Воге, французского дипломата и писателя, который видел Чехова «фотографом, что всегда $<\ldots>$ захватывает реальные сцены из жизни и развивает их искусством». Худериас указал и на позицию критиков, находящих драматургию Чехова «серой», излишне пессимистической, «неприятной», лишённой радости и света. Он даже привел цитату одного исследователя, сравнивающего произведения русского писателя с кино, которое в начале прошлого века было лишено красок. Вместе с тем исследователь отметил, что «качество использования незначительных вещей в сочетании с однородностью... стиля» позволяет рассказам и пьесам Чехова создавать от прочтения «уникальное впечатление», которое «читатель не может объяснить без предварительной подготовки». [17]

В книге «Чехов и мировая литература» Н.А. Матяш обозначила, что испанской культуре Чехова открыл журнал «La España moderna», на страницах которого с января 1903 г. печатались произведения русского писателя: сначала повесть «Дуэль» и рассказ «Княгиня», а затем и некоторые другие. Первые пьесы, вероятно, издаются в 1910 г. в Барселоне, затем в 20-е гг. выходит целый ряд сборников. На сцене испанских театров появляются первые экспериментальные постановки чеховской драматургии. [2]

Важными в увеличении интереса к творчеству А.П. Чехова в Испании оказываются 1960-е гг. Прежде всего, нужно отметить, что в 1959 г., в преддверии празднования юбилея писателя, в Мадриде издаётся «Полное собрание пьес Чехова», а спустя несколько лет - «Полное собрание рассказов». В честь столетия русского писателя первые страницы январского номера журнала «El Correo de la UNESCO» за 1960 г. были посвящены Чехову: испанская общественность получила возможность ознакомиться с советским чеховедением через переводную статью М.Е. Елизаровой и европейским 
взглядом на чеховские пьесы через резюме радиопередачи, проведённой английской актрисой и драматургом Паулиной Бентли. П. Бентли указывает, что «Чайка», «Дядя Ваня», «Три сестры» и «Вишнёвый сад» за пределами родины Чехова «почти всегда представлены с определённой настойчивостью в их незначительном тоне и несколько бессвязном содержании» [7]. Действительно, в первых испанских изданиях чеховских текстов мы встречаемся исключительно с подобной позицией, о чём свидетельствуют небольшие статьи-предисловия к сборникам. Так, например, Сатурно Хименес, переводивший Чехова в 1910-1920-е гг., называет «Вишнёвый сад» лишь «наброском к большой картине». Как замечала ещё Н.А. Матяш, Хименес видит русского писателя обыкновенным «бытописателем», «которому русская действительность давала богатый материал». Талант Чехова он признаёт лишь в области создания «галереи комических образов», при этом совершенно очевидно, что глубинная и подчас сугубо философская суть его произведений испанскому переводчику не видна [2]. Но в 60-е гг. подобные умозаключения открыто называются ошибочными, и в том же обзоре Паулины Бентли мы можем прочитать следующее: «На первый взгляд, эти рассказы кажутся случайно написанными, но в действительности их конструкция настолько ясна и прозрачна, что кажущемуся отсутствию формы невозможно подражать» [7].

В честь юбилея Чехова на сценах многих театров мира ставили его пьесы. Примечательно, что режиссёр постановки «Вишнёвого сада» в мадридском театре «María Guerrero» Хосе Луис Алонсо воспользовался именно новым переводом окончивших филологический факультет МГУ Хосефины Санчес Педреньо и Викториано Имберто, а не существовавшим вариантом ранее упомянутого С. Хименеса [12].

С 1963 г. появляются первые телевизионные адаптации чеховской драматургии: в рамках телепроектов «Primera fila» («Первый ряд») и «Estudio 3» («Студия 3») испанцы, не выходя из дома, на экранах телевизоров смогли увидеть «Дядю Ваню» и «Свадьбу» [8; 15]. Богатым на экранизации становится 1969 г., в котором телезрители увидели сразу пять новых фильмов. Режиссёром трёх работ является Франциско Абад. Предположительно, два фильма - «El Drama» («Драма») и «La Dote» («Приданое») - вышли на телевизионные экраны друг за другом в первом квартале года. Они вошли в серию под названием «Cuentos de Chéjov» («Чеховские рассказы»). Другая экранизация - «Тío Vania» («Дядя Ваня») - реализовалась в рамках своеобразной телепередачи-сериала «Teatro de siempre» («Вечный театр») и была запущена в эфир 11 ноября 1969 г. [8; 15]. Под фольклорную музыку на фоне вступительных титров и демонстрации усадьбы первой жены профессора Серебрякова закадровый голос знакомит зрителя с краткой биографической справкой А.П. Чехова и даже даёт сжатую оценку его творчества. Прозу и драматургию Чехова диктор называет «меланхолическим раздумьем, не лишённым горького юмора, о человеческом поведении», отмечает, что его произведения иллюстрируют «врага пафоса и надменности». Вслед за советской критической традицией мы слышим слова: «Он хочет показать жизнь такой, какая она есть... Предъявляет людей за едой, ведением насущных бесед, скучающих». Зрителей знакомят с чеховским «приёмом поэтического реализма», заключающимся в «непрямом действии»: «пока персонажи говорят на сцене о разных пустяках, важные вещи происходят снаружи - необходимо видеть значимость внешних звуков: ржание лошадей, выстрел, удары топоров, вырубающих вишнёвый сад» [16]. Несомненно, такое внимание к творчеству А.П. Чехова свидетельствует о переходе на качественно новое отношение испанцев к русскому драматургу.

Режиссёр Альберто Гонсалес Верхель, с успехом поставивший ещё в 1959 г. «Чайку» в барселонском театре «Виндзор», через 10 лет выпускает на экраны испанского телевидения «Вишнёвый сад», а годом позже - «Три сестры» [8; 15]. Режиссёр высоко ценил талант Чехова и наставлял своих коллег на правильное прочтение его драматургии, указывая на то, что «реализм его пьес не должен заслонять их глубину и достоверность» [2].

Интересным для размышления об отношении испанской культуры к чеховским произведениям в 60-е гг. прошлого века представляется тот факт, что телепроекты, в рамках которых были экранизированы его пьесы, неоднократно назывались «специализирующимися на жанре ужасов» [8]. А в крупнейшей мировой базе данных о кинематографе «IMDb» («Internet Movie Database») в описаниях испанских экранизаций того периода в определении жанра часто встречается следующее: «Комедия. Драма. Ужасы» [15].

В 1970-е гг. интерес к драматургии Чехова сохраняется, однако, возможно, это следует считать лишь инертным последствием явного возвышения фигуры писателя в предыдущем десятилетии. Попрежнему успешны постановки его пьес на испанской сцене, и отдельного внимания заслуживает ре- 
жиссёр В. Лейтон, в 1978 г. в одном из мадридских театров показавший публике пьесу «Дядя Ваня». Он считал, что «в этой поэтической пьесе... почти слышно, как думают персонажи» [2]. В. Лейтон отмечал также, что зритель оказывается на своего рода суде жизни, где каждому персонажу он должен вынести оправдательный или обвинительный приговор.

Для телезрителя в 70-х гг. выходит шесть кинопроизведений под руководством различных режиссёров - это «Tres hermanas» («Три сестры»), «Flores tardías» («Цветы запоздалые»), «La gaviota» («Чайка»), «La sala número 6» («Палата №6»), «El tío Vania» («Дядя Ваня») и «El orador» [6; 8; 15]. В последующие годы интерес экранной индустрии к Чехову угасает. С падением франкистского режима Испания всецело входит в мировое культурное, экономическое, научное и политическое пространство. Десятки лет своеобразной изоляции привели к определенным последствиям. В театральном искусстве совершается переворот: на первый план выходят экспериментаторы, ещё не имеющие за своими плечами должного опыта. Постановки чеховских пьес оказываются провальными, и всё творчество русского драматурга отходит на второй план, оказывается более материалом дидактическим, нежели «прокатным».

Но полноценное вступление страны в европейское сообщество благотворно повлияло на развитие книжного дела: с 80-х гг. XX в. для испанской аудитории издаются не только собрания сочинений А.П. Чехова, но и его письма. Активизация книгоиздания важной является для нас потому, что появляется возможность отследить в комментариях и предисловиях к этим сборникам отношение к творчеству русского писателя представителей испанского литературоведения.

Так, особого внимания заслуживает предисловие к изданной в 1981 г. в барселонском издательстве книге «Антон Павлович Чехов. Ранние рассказы», которое подготовлено испанским критиком Хосе Марией Вальверде Пачеко. Как и Хулиан Худериас в своё время, Вальверде начинает с описания биографии писателя, уделяя особое внимание происхождению писателя, однако в отличие от своего коллеги он позволяет себе значительно большую самостоятельность в суждениях. По мнению испанского критика, на выбор жанра юмористического рассказа повлияла нечёткая позиция Чехова как личности по отношению к политическим, философским и религиозным убеждениям. Вальверде отмечает также, что в отличие от своих современников, того же А. Мачадо, русский писатель не рассматривал творчество как выражение своего «Я», и «это проявлялось в его стилистической сдержанности». «Сдержанность» Чехова порождает лаконизм, который не позволяет его произведениям стать «всеобъемлющим документом о русской жизни той эпохи». Обращаясь к пьесам Чехова, критик лишь указывает на приём «скрытого действия», который режиссёрам, претендующим на качественную постановку, необходимо всегда видеть и иметь в виду. [3]

В 80-е гг. отдельными книгами, а также в составе сборников публикуются различные произведения А.П. Чехова и его переписка с родными и друзьями. Нельзя сказать, что испанская сцена и кинематограф забыли русского драматурга, однако особо громких и выдающихся постановок не наблюдается. У испанских читателей, зрителей, критиков Чехов постепенно занимает свою нишу в числе зарубежных авторов. Начинают возникать различные параллели: Чехов - Лорка, Чехов - Саймон и др. [4; 15] Вторая параллель кажется весьма интересной, поскольку она вышла за пределы теории и реализовала себя практически в фильме-мюзикле режиссёра Францеска Нел-ло и Пере Планелла, который появился на телевизионных экранах в 1987 г. под названием «El bon doctor» («Добрый доктор») и явился неким соединением пьесы Нила Саймона и рассказов А.П. Чехова [15]. Собственно, это ещё один из экспериментов, которые всё более и более предпринимаются с творчеством Чехова в Испании.

Новый всплеск в прессе вокруг имени Чехова случился в конце 2013 г. когда образованное в 1999 г. в Мадриде издательство «Páginas de Espuma» («Страницы из пены») анонсировало скорый выход первого из четырёх томов нового собрания сочинений русского писателя. Каждый том насчитывал около 1200 страниц, редактором издания являлся испанский писатель и литературный критик Пауль Бьехо. Основным принципом формирования издания явилась хронология написания произведений. По замыслу редактора, испанский читатель должен был получить право увидеть эволюцию творчества Чехова в верной временной последовательности. «Páginas de Espuma» утверждает, что данное издание является самым полным собранием всех произведений русского писателя и драматурга, поскольку включает в себя ряд рассказов и очерков, которые ранее никогда не переводились на испанский язык. Здесь представлены произведения в переводе различных авторов, поэтому Пауль Бьехо заключает, что их труд может считаться иллюстрацией «некой истории переводов Чехова в Испании» [14]. 
Описывая данное событие, журналист одной из крупнейших испанских газет «El País» Хосе Андрес Рохо применил по отношению к русскому писателя следующую метафору: «Если бы душа была часами, то Чехов был бы часовщиком» [14]. А информационный портал «Sputnik» («Спутник») высказал мнение о том, что «интерес к Чехову возникает в моменты общественного неспокойствия» и опубликовал для своих читателей перевод интервью о творчестве А.П. Чехова с доцентом кафедры истории русской литературы филологического факультета МГУ Р.Б. Ахметшиным [10].

В последние годы имя Чехова периодически оказывалось на слуху у испанской общественности в связи с чередой новых экспериментальных постановок на сценах столичных и провинциальных театров. В 2019 г. в Главном театре Валенсии небезуспешно прошла постановка Виктора Санчеса Родригеса, имеющая название по первым строчкам популярной на то время группы Haddaway«What is love? Baby don't hurt me» («Что такое любовь? Малышка, не причиняй мне боль») - и являющаяся свободным прочтением пьесы «Иванов». Режиссёр пытался адаптировать «чеховскую меланхолию» к современным реалиям испанского общества. Он отмечал, что русский драматург изобразил людей на переломе эпох, «непонимающих, что их ждёт в будущем». То же состояние непонимания и переживания он видит и у людей XXI в. «Нашей главной заботой сегодня являются <...> климатические изменения и избыток пластиковой продукции, используемой в быту», - говорит режиссёр [9]. Поднять эти проблемы позволяют не только некоторые изменения текста самой пьесы, но и сами декорации на сцене. Менее эксцентрично подходит к вопросу постановки чеховских пьес другой испанский режиссёр - Алекс Ригола. В марте этого года он сообщил о готовящейся постановке «Чайки» на сцене одного из барселонских театров. Это его третье обращение к Чехову за всю карьеру. Особенностью его работ является необычный подбор актёров, жизненные судьбы которых должны определённым образом совпадать с судьбами изображаемых ими персонажей. В частности, Алекс Ригола признаётся, что позволяет себе иногда небольшие вольности, вплетая в пьесы Чехова некоторые факты из жизней актёров. Режиссёр находит для себя самым поразительным «яркую самовыраженность персонажей Чехова» $[11 ; 13]$.

Пройдя более чем вековой путь осознания испанским обществом, А.П. Чехов является на сегодня примером и символом новаторства, русским писателем, вдохновляющим испанских художников на смелые и революционные эксперименты.

\section{СПИСОК ИСТОЧНИКОВ И ЛИТЕРАТУРЫ}

1. Жарова Г.Д. Зарубежные писатели о творчестве Чехова (материалы к беседе). URL: http://taglib.ru/chehov/ zarlit.html

2. Матяш Н.А. Чехов в Испании. І. 1887-1980 // Чехов и мировая литература. Кн. 2. М.: ИМЛИ РАН, 2005. C. $449-458$.

3. Могильный О.Т., Тамарли Г.И. Чехов в Испании. II. 1981-2001 // Чехов и мировая литература. Кн. 2. М.: ИМЛИ РАН, 2005. С. 459-466.

4. Могильный О.Т., Тамарли Г.И. Чехов и Лорка // Чехов и мировая литература. Кн. 2. М.: ИМЛИ РАН, 2005. C. $467-476$.

5. Чехов и зарубежье // URL: https://russkiymir.ru/publications/85377/

6. Anton Chéjov: adaptaciones cinematográficas. URL: https://www.alohacriticon.com/literatura/adaptacionescinematograficas/anton-chejov-cine/

7. Bentley P. El camino de la esperanza: la vida y la obra de Antón Chejov // El Correo de la UNESCO. № 1. 1960. P. 4-12.

8. Corporación de Radio y Televisión Española // URL: https://www.rtve.es/

9. Devís A.G. La trágica melancolía de Chejov vista desde nuestros días por Víctor Sánchez Rodríguez. URL: https://valenciaplaza.com/la-tragica-melancolia-de-chejov-vista-desde-nuestros-dias-por-victor-sanchez-rodriguez

10. El interés por Chéjov coincide con momentos de agitación social. URL: https://mundo.sputniknews.com/opinion/ 20131202158687871/

11. García R. Álex Rigola encierra en una caja la desolación vital de Chéjov. URL: https://elpais.com/cultura/ 2017/11/12/actualidad/1510471563_950835.html

12. Marquerie A. Estreno de «El jardín de los cerezos», de Chejov, en el María Guerrero // ABC Madrid. Ed. de 29.10.1960. 1960. P. 75.

13. Ordóñez M. Chéjov y la banda de Rigola. URL: https://elpais.com/cultura/2020-03-18/chejov-y-la-banda-derigola.html

14. Rojo J.A. Antón Chéjov, el relojero. URL: https://elpais.com/cultura/2013/12/01/actualidad/ 1385915588_167250.html

15. The Internet Movie Database. URL: https://www.imdb.com/?ref_=nv_home 
16. Tío Vania [художественный фильм]. 1969. Primera fila. TVE. URL: https://www.rtve.es/alacarta/videos/teatro-enel-archivo-de-rtve/teatro-siempre-tio-vania-1969/1880473/

17. Juderias y Loyot J. Tchejoff // La lectura. № 1. 1902. P. 165-170.

Поступила в редакцию 20.02.2020

Огальцев Антон Сергеевич, аспирант кафедры истории русской литературы и теории литературы

ФГБОУ ВО «Удмуртский государственный университет»

426034, Россия, г. Ижевск, ул. Университетская, 1 (корп. 2)

E-mail: senyor-ogaltsev@hotmail.com

\title{
A.S. Ogaltsev \\ PECULIARITIES OF COMPREHENSION OF CHEKHOV'S WORKS IN SPAIN
}

\author{
DOI: $10.35634 / 2412-9534-2020-30-6-1072-1077$
}

The article deals with the process of comprehension of A.P. Chekhov's works in the Spanish culture. It's based on Russian and foreign sources. The author of the article demonstrates the most significant moments in the understanding of the Russian writer by Spanish literary critics, theater directors and film directors. The article contains a brief overview of key periodicals and books, plays and film adaptations that illustrate the evolution of comprehension of Chekhov's works. Citations of Spanish culture figures, critics, translators and journalists are given by author's translation from their works and interviews. The article illustrates the period from the first mention of Chekhov's name in the Spanish press in 1894 to the nowadays. The author pays special attention to the first screen versions of the Russian playwright's plays and the most eccentric experimental staging in the capital and provincial theaters of Spain.

Keywords: Chekhov's works, Chekhov and Spain, Chekhov and foreign countries, Chekhov's film adaptation, plays of Chekhov.

\section{REFERENCES}

1. Zharova G.D. Zarubezhnye pisateli o tvorchestve CHekhova (materialy k besede) [Foreign writers about works of Chekhov (materials for discussion)]. URL: http://taglib.ru/chehov/zarlit.html (In Russian).

2. Matyash N.A. Chekhov v Ispanii [Chekhov in Spain]. I. 1887-1980// CHekhov i mirovaya literatura [Chekhov and universal literature]. Book 2. Moskow: IMLI RAN, 2005. P. 449-458. (In Russian).

3. Mogil'nyj. O.T., Tamarli G.I. Chekhov v Ispanii [Chekhov in Spain]. I. 1981-2001// Chekhov i mirovaya literature [Chekhov and world literature]. Book 2. Moskow: IMLI RAN, 2005. P. 459-466. (In Russian).

4. Mogil'nyj. O.T., Tamarli G.I. Chekhov i Lorka [Chekhov and Lorka] // Chekhov i mirovaya literature [Chekhov and world literature]. Book 2. Moskow: IMLI RAN, 2005. P. 467-476. (In Russian).

5. Chekhov i zarubezh'e [Chekhov and foreign countries]. URL: https://russkiymir.ru/publications/85377/ (In Russian).

6. Anton Chéjov: adaptaciones cinematográficas [Anton Chekhov: screen versions]. URL: https:/www.alohacriticon.com/ literatura/adaptaciones-cinematograficas/anton-chejov-cine/ (In Russian).

7. Bentley P. El camino de la esperanza: la vida y la obra de Antón Chejov [The way of the hope: life and works of Anton Chekhov] // El Correo de la UNESCO [The Unesco courier]. № 1. 1960. P. 4-12. (In Spanish).

8. Corporación de Radio y Televisión Española [Spanish Radio and Television Corporation]. URL: https://www.rtve.es/ (In Spanish).

9. Devís A.G. La trágica melancolía de Chejov vista desde nuestros días por Víctor Sánchez Rodríguez [The tragic melancholy of Chekhov by the nowadays' view of Victor Sanches Rodroges] // URL: https://valenciaplaza.com/latragica-melancolia-de-chejov-vista-desde-nuestros-dias-por-victor-sanchez-rodriguez (In Spanish).

10. El interés por Chéjov coincide con momentos de agitación social [Interest for Chekhov coinced with social anxiety]. URL: https://mundo.sputniknews.com/opinion/20131202158687871/ (In Spanish).

11. García R. Álex Rigola encierra en una caja la desolación vital de Chéjov [Alex Rigola closes life's sorrow of Chekhov into a box]. URL: https://elpais.com/cultura/2017/11/12/actualidad/1510471563_950835.html (In Spanish).

12. Marquerie A. Estreno de «El jardín de los cerezos», de Chejov, en el María Guerrero [A Premiere of «The Cherry Orchard» of Chekhov in the Maria Guerrero Theatre] // ABC Madrid. Ed. de 29.10.1960. 1960. P. 75. (In Spanish).

13. Ordóñez M. Chéjov y la banda de Rigola [Chekhov and the Rigola’s band]. URL: https://elpais.com/cultura/202003-18/chejov-y-la-banda-de-rigola.html (In Spanish).

14. Rojo J.A. Antón Chéjov, el relojero [Anton Chekhov: the watchmaker]. URL: https:/elpais.com/cultura/ 2013/12/01/actualidad/1385915588_167250.html (In Spanish). 
15. The Internet Movie Database. URL: https://www.imdb.com/?ref_=nv_home (In Spanish).

16. Tío Vania [художественный фильм]. [Uncle Vania, film] 1969. Primera fila. TVE. URL: https://www.rtve.es/ alacarta/videos/teatro-en-el-archivo-de-rtve/teatro-siempre-tio-vania-1969/1880473/ (In Spanish).

17. Juderias y Loyot J. Tchejoff [Chekhov] // La lectura [Reading]. № 1. 1902. P. 165-170. (In Spanish).

Received 20.02.2020

Ogaltsev A.S., postgraduate student at Department of history of the Russian literature and theory of literature Udmurt State University

Universitetskaya st., 1/2, Izhevsk, Russia, 426034

E-mail: senyor-ogaltsev@hotmail.com 